\title{
Varying the ratio of Lys:Met while maintaining the ratios of Thr:Phe, Lys:Thr, Lys:His, and Lys:Val alters mammary cellular metabolites, mammalian target of rapamycin signaling, and gene transcription
}

\author{
X. Dong, ${ }^{*} †$ Z. Zhou, $† \S$ B. Saremi, $\ddagger$ A. Helmbrecht, $\ddagger$ Z. Wang,${ }^{* 1}$ and J. J. Loor ${ }^{1}$ \\ *Key Laboratory for Animal Disease-Resistance Nutrition of China Ministry of Education, Animal Nutrition Institute \\ of Sichuan Agricultural University, Ya'an, 625014, Sichuan Province, P.R. China \\ †Mammalian NutriPhysioGenomics, Department of Animal Sciences and Division of Nutritional Sciences, University of Illinois, Urbana 61801 \\ ‡Evonik Nutrition and Care GmbH, 63457 Hanau-Wolfgang, Germany \\ §Department of Animal and Veterinary Sciences, Clemson University, Clemson, SC 29634
}

\section{ABSTRACT}

Amino acids are not only precursors for but also signaling molecules regulating protein synthesis. Regulation of protein synthesis via AA occurs at least in part by alterations in the phosphorylation status of mammalian target of rapamycin (mTOR) pathway proteins. Although the ideal profile of Lys:Met to promote milk protein synthesis during established lactation in dairy cows has been proposed to be $3: 1$, aside from being the most-limiting AA for milk protein synthesis, the role of Met in other key biologic pathways such as methylation is not well characterized in the bovine. The objective of this study was to determine the influence of increasing supplemental Met, based on the ideal 3:1 ratio of Lys to Met, on intracellular metabolism related to protein synthesis and mTOR pathway phosphorylation status. MAC-T cells, an immortalized bovine mammary epithelial cell line, were incubated $(\mathrm{n}=5$ replicates/ treatment) for $12 \mathrm{~h}$ with 3 incremental doses of Met while holding Lys concentration constant to achieve the following: Lys:Met 2.9:1 (ideal AA ratio; IPAA), Lys:Met 2.5:1 (LM2.5), and Lys:Met 2.0:1 (LM2.0). The ratios of Thr:Phe (1.05:1), Lys:Thr (1.8:1), Lys: His (2.38:1), and Lys:Val (1.23:1) were the same across the 3 treatments. Applying gas chromatography-mass spectrometry metabolomics revealed distinct clusters of differentially concentrated metabolites in response to Lys:Met. Lower Phe, branched-chain AA, and putrescine concentrations were observed with LM2.5 compared with IPAA. Apart from greater intracellular Met concentrations, further elevations in Met level (LM2.0) led to greater intracellular concentrations of nonessential AA (Pro, Glu, Gln, and Gly) compared

\footnotetext{
Received June 19, 2017.

Accepted October 26, 2017.

${ }^{1}$ Corresponding authors: wangzs@sicau.edu.cn and jloor@illinois.
} edu with IPAA and greater essential AA (EAA; Met, Ile, and Leu) and nonessential AA (Pro, Gly, Ala, Gln, and Glu) compared with LM2.5. However, compared with IPAA, mRNA expression of $\beta$-casein and AA transporters (SLC7A5, SLC36A1, SLC38A2, SLC38A9, and $S L C 43 A 1)$ and mTOR phosphorylation were lower in response to LM2.5 and LM2.0. Overall, the results of this study provide evidence that increasing Met while Lys and the ratios of Phe, Thr, His, and Val relative to Lys were held constant could increase the concentration and utilization of intracellular EAA, in particular branched-chain AA, potentially through improving the activity of AA transporters partly controlled by mTOR signaling. Because EAA likely are metabolized by other tissues upon absorption, a question for future in vivo studies is whether formulating diets for optimal ratios of EAA in the metabolizable protein is sufficient to provide the desired levels of these AA to the mammary cells.

Key words: lysine:methionine ratio, metabolomics, milk protein synthesis, MAC-T cell

\section{INTRODUCTION}

Methionine (Met) and lysine (Lys) are the mostlimiting AA in a large range of diets for dairy cows (Osorio et al., 2013); therefore, their supplementation is an effective approach to balance AA for optimal milk production (Wang et al., 2010). Previous research indicated that an approximately 3:1 ratio of Lys to Met in the MP could be the ideal or near-ideal profile of these AA to improve milk protein synthesis (Armentano et al., 1997; Rulquin et al., 2006; Wang et al., 2010; Osorio et al., 2013). Focus on the ratio of Lys to Met that is available for absorption (Donkin et al., 1989; Rulquin et al., 2006; Nan et al., 2014) is based on the idea that such values could be of practical use when formulating dairy diets. Whether the optimal Lys:Met ratio of approximately $3: 1$ is able to elicit a physiologic response 
related to AA metabolism and utilization within mammary epithelial cells (MEC) is not well known, but clearly such data are of importance in the context of understanding protein synthesis and degradation in the mammary gland (Manjarin et al., 2014).

Metabolomics is an emerging field that relies on tools such as ${ }^{1} \mathrm{H}$-nuclear magnetic resonance, GC-MS, and liquid chromatography tandem-MS for identifying alterations in metabolites under different physiologic conditions (Ametaj et al., 2010). The data obtained can subsequently be integrated through multivariate analysis. These approaches have already been applied in ruminant nutrition to study the relationships between nutritional management and metabolic profiling in milk, blood plasma, ruminal fluid, urine, rumen epithelial tissue, and even gut contents (Dumas et al., 2006; Bertram et al., 2009; Sun et al., 2015; Yang et al., 2016). To our knowledge, profiling of the MEC metabolome has yet to be performed in nutrigenomics studies. In addition to the well-established role of Met and Lys in protein synthesis, Met also regulates multiple pathways involved in synthesis and metabolism of phospholipids, carnitine, creatine, and polyamine synthesis in tissues (Armentano et al., 1997; Manjarin et al., 2014). Thus, it is likely that altering the availability of Met within MEC could elicit metabolome-wide changes of physiologic relevance.

The stimulation of protein synthesis via certain EAA is regulated at least in part by alterations in the mammalian target of rapamycin (mTOR) signaling pathway (Xie and Proud, 2014). Activated mTOR can phosphorylate a variety of downstream eukaryotic translation initiation (eIF) and elongation (eEF) factors, including 4EBP1, S6K1, RPS6, eIF2 $\alpha$, and eEF2 (Appuhamy et al., 2011). The kinase Akt upstream of mTOR plays an important role in the regulation of mTOR activity by sensing signals involved in cell growth, proliferation, differentiation, survival, and apoptosis (Reddi et al., 2016). Although phosphorylation level of mTOR in MEC is influenced by the Lys: Met ratio (Nan et al., 2014), the relationship between the Lys:Met ratio when the supply of Met is increased and the responses of the mTOR pathway to an increase in the supply of Met when Lys and other AA are held constant are unknown. Specifically, it is unclear whether increasing Met can further enhance the activity of mTOR and what outcome it may have on mRNA expression and metabolic profiles in MEC.

We hypothesized that changing the Lys:Met ratio by increasing Met supplementation could stimulate casein protein mRNA expression in MEC not only through changes in protein and phosphorylation status of the mTOR pathway but also through alterations in mRNA expression and intracellular AA absorption and metab- olism activity. The overall objectives of this study were to determine whether increasing Met in a medium of MAC-T cells, a nonsecretory bovine mammary cell line, from the ideal profile of Lys to Met $(\sim 3: 1)$ could (1) alter the MEC metabolome, (2) regulate mTOR pathway protein expression and phosphorylation status, and (3) alter mRNA expression of key AA transporters and casein.

\section{MATERIALS AND METHODS}

\section{Treatments and Experimental Design}

To determine the effect of Lys:Met ratio on gene expression, MAC-T cells in 6-well plates were serumstarved overnight and then cultured for $12 \mathrm{~h}$ in serumfree media with 3 treatments each with 5 replicates. All treatment lactogenic media were prepared as described in previous work from our laboratory (Kadegowda et al., 2009), except that high-glucose Dulbecco's modified Eagle's medium devoid of EAA (custom made from Gibco, Invitrogen, Carlsbad, CA) was used to replace minimum essential medium/Earle's balanced salts HyQ. Individual EAA (L-isomer) purchased from Sigma-Aldrich (St. Louis, MO) were supplemented into the custom high-glucose Dulbecco's modified Eagle's medium. The treatments were designed as follows: control medium with the ideal AA ratio (IPAA; Lys:Met 2.9:1; Thr:Phe 1.05:1; Lys:Thr 1.8:1; Lys:His 2.38:1; Lys:Val 1.23:1), Lys:Met 2.5:1 (LM2.5), and Lys:Met 2.0:1 (LM2.0) were prepared by increasing only Met supplementation and keeping the other AA ratios the same as in IPAA (Table 1). Cells were incubated at $37^{\circ} \mathrm{C}$ in an atmosphere of $5 \% \mathrm{CO}_{2}$ and air. After $12 \mathrm{~h}$ of treatment, cells were scraped using a cell lifter in 1

Table 1. Amino acid composition of the ideal AA mixture (Lys:Met 2.9:1; IPAA) and the treatments containing Lys:Met at 2.5:1 (LM2.5) and 2.0:1 (LM2.0)

\begin{tabular}{lccc}
\hline AA & IPAA $^{1,2,3}$ & LM2.5 & LM2.0 \\
\hline Lys $(\mu \mathrm{g} / \mathrm{mL})$ & 175 & 175 & 175 \\
Met $(\mu \mathrm{g} / \mathrm{mL})$ & 60 & 70 & 87 \\
Lys:Met & $2.9: 1$ & $2.5: 1$ & $2.0: 1$ \\
Thr $(\mu \mathrm{g} / \mathrm{mL})$ & 97 & 97 & 97 \\
Phe $(\mu \mathrm{g} / \mathrm{mL})$ & 93 & 93 & 93 \\
His $(\mu \mathrm{g} / \mathrm{mL})$ & 74 & 74 & 74 \\
Val $(\mu \mathrm{g} / \mathrm{mL})$ & 142 & 142 & 142 \\
Ile $(\mu \mathrm{g} / \mathrm{mL})$ & 121 & 121 & 121 \\
Leu $(\mu \mathrm{g} / \mathrm{mL})$ & 206 & 206 & 206 \\
Arg $(\mu \mathrm{g} / \mathrm{mL})$ & 84 & 84 & 84 \\
Trp $(\mu \mathrm{g} / \mathrm{mL})$ & 16 & 16 & 16 \\
\hline${ }^{1}$ NRC $(2001)$. & & & \\
${ }^{2}$ Haque et al. $(2012)$. & & & \\
${ }^{3}$ Haque et al. $(2013)$. & &
\end{tabular}

Journal of Dairy Science Vol. 101 No. 2, 2018 
$\mathrm{mL}$ of QIAzol reagent (Invitrogen) and stored at $-80^{\circ} \mathrm{C}$ until gene expression analysis.

For protein phosphorylation and expression of Akt, mTOR, 4EBP1, S6K1, rpS6, eIF2 $\alpha$, and eEF2 in the mTOR pathway, the experimental design and treatments were the same as for gene expression, but 6 -well plates were placed on ice and cells were collected by scraping into ice-cold M-PER mammalian protein extraction reagent (cat. no. 78501, Thermo Scientific, Waltham, MA) containing 1\% halt protease and phosphatase inhibitors cocktail (cat. no. 78440, Thermo Scientific). Lysates were centrifuged at $14,000 \times g$ for 10 min at $4^{\circ} \mathrm{C}$, and then the supernatants were harvested and stored at $-80^{\circ} \mathrm{C}$. The bicinchoninic acid protein kit (cat. no. 23227, Thermo Scientific) was used for measuring protein concentration.

For cellular metabolite profiling, the experimental design and treatments were similar to those for gene expression. After $12 \mathrm{~h}$ of culture, MAC-T cells were collected into $1.5-\mathrm{mL}$ tubes with $350 \mu \mathrm{L}(60 \%)$ of precooled $\left(-20^{\circ} \mathrm{C}\right)$ methanol and stored at $-80^{\circ} \mathrm{C}$.

\section{Metabolomics Analysis}

Metabolites were extracted with a 5 -min sonication (30-s pulse on followed by 30-s pulse off) with the QSonica Q700 homogenizer (QSonica LLC, Newtown, CT) in $1 \mathrm{~mL}$ of $70 \%$ methanol. Supernatants were collected by centrifugation $(5 \mathrm{~min}$ at $15,000 \times$ $g$ ); dried and derivatized with $50 \mu \mathrm{L}$ of methoxyamine hydrochloride (Sigma-Aldrich; $20 \mathrm{mg} / \mathrm{mL}$ in pyridine) for $60 \mathrm{~min}$ at $50^{\circ} \mathrm{C}$ and then with $50 \mu \mathrm{L}$ of $N$-methyl- $N$ (trimethylsilyl)trifluoroacetamide $+1 \%$ chlorotrimethylsilane (Thermo Scientific) at $70^{\circ} \mathrm{C}$ for $120 \mathrm{~min}$; and subsequently incubated for $2 \mathrm{~h}$ at room temperature. Five microliters of the internal standard (hentriacontanoic acid, $10 \mathrm{mg} / \mathrm{mL}$ ) was added to each sample before derivatization.

Metabolite profiles were acquired using a GC-MS system (Agilent Technologies, Santa Clara, CA) consisting of an Agilent 7890 gas chromatograph, an Agilent 5975 mass selective detector (MSD), and an HP 7683B autosampler. Gas chromatography was performed on a ZB-5MS $(60 \mathrm{~m} \times 0.32 \mathrm{~mm}$ i.d., $0.25 \mu \mathrm{m}$ film thickness) capillary column (Phenomenex, Torrance, CA). The inlet and MS interface temperature was $250^{\circ} \mathrm{C}$, and the ion source temperature was adjusted to $230^{\circ} \mathrm{C}$. An aliquot of $1 \mu \mathrm{L}$ was injected at a split ratio of 7:1. Helium was the carrier gas, and flow was kept at a constant rate of $2 \mathrm{~mL} / \mathrm{min}$. The temperature program was $5 \mathrm{~min}$ of isothermal heating at $70^{\circ} \mathrm{C}$ followed by an oven temperature increase of $5^{\circ} \mathrm{C} / \mathrm{min}$ to $310^{\circ} \mathrm{C}$ and a final $10 \mathrm{~min}$ at $310^{\circ} \mathrm{C}$. The mass spectrometer was operated in positive electron impact mode at $69.9 \mathrm{eV}$ of ionization energy at a scan range of mass:charge ratio $(\mathrm{m} / \mathrm{z}) 30$ to 800 .

The spectra of all chromatogram peaks were evaluated with the AMDIS 2.71 (National Institute of Standards and Technology, Gaithersburg, MD) using a custom-built database (460 unique metabolites). All known artificial peaks not found in the database were removed before data mining. To allow comparisons between samples, all data were normalized to the internal standard in each chromatogram and the cell dry weight. The instrument variability was within the standard acceptance limit (5\%).

\section{RNA Extraction and Real-Time PCR Analysis}

Total cellular RNA was extracted by the RNeasy Mini columns (Qiagen, Valencia, CA). Concentrations of RNA were quantified with an ND-1000 spectrophotometer (NanoDrop Technologies, Wilmington, DE). The Agilent 2100 bioanalyzer (Agilent Technologies) was used to determine the RNA integrity number, and the RNA integrity number value was $>8.0$ for all samples used. A portion of the RNA was diluted to 100 $\mathrm{ng} / \mu \mathrm{L}$ using RNase-free water before cDNA synthesis.

Sufficient cDNA was prepared to test all target genes. The cDNA from 5 replicates per treatment was synthesized by RT-PCR using $100 \mathrm{ng}$ of RNA, $1 \mu \mathrm{L}$ of Random Primers (Roche, Basel, Switzerland), and 9 $\mu \mathrm{L}$ of RNase-free water. The mixture was incubated at $65^{\circ} \mathrm{C}$ for $5 \mathrm{~min}$ in an Eppendorf Mastercycler Gradient (Fisher Scientific, Waltham, MA). A total of $9 \mu \mathrm{L}$ of master mix comprising $4 \mu \mathrm{L}$ of $5 \times$ First-Strand buffer (Fermentas, Pittsburgh, PA), $1 \mu \mathrm{L}$ of oligo dT18, $2 \mu \mathrm{L}$ of $10 \mathrm{mM}$ deoxynucleotide 5 -triphosphate mix (Invitrogen), $0.25 \mu \mathrm{L}$ of reverse aid RT (Fermentas), $0.125 \mu \mathrm{L}$ of RNase inhibitor (Fermentas), and 1.625 $\mu \mathrm{L}$ of RNase-free water were added. The reaction was conducted using the following temperature program: $25^{\circ} \mathrm{C}$ for $5 \mathrm{~min}, 42^{\circ} \mathrm{C}$ for $60 \mathrm{~min}$, and $70^{\circ} \mathrm{C}$ for $5 \mathrm{~min}$. The cDNA was then diluted 1:4 with RNase-free water.

For real-time PCR, $4 \mu \mathrm{L}$ of diluted cDNA was combined with $6 \mu \mathrm{L}$ of a mixture comprising $5 \mu \mathrm{L}$ of $1 \times$ SYBR Green Master Mix (Quanta, Gaithersburg, MD), $0.4 \mu \mathrm{L}$ each of $10 \mu \mathrm{M}$ forward and reverse primers, and $0.2 \mu \mathrm{L}$ of RNase-free water. The reactions of real-time PCR were performed in an ABI Prism 7900 HT SDS instrument (Applied Biosystems, Foster City, CA) with the following program: $95^{\circ} \mathrm{C}$ for $5 \mathrm{~min}, 40$ cycles at $95^{\circ} \mathrm{C}$ for $15 \mathrm{~s}$, and $60^{\circ} \mathrm{C}$ for $30 \mathrm{~s}$. The presence of a single PCR product was verified by the dissociation protocol at $95^{\circ} \mathrm{C}$ for $15 \mathrm{~s}, 65^{\circ} \mathrm{C}$ for $15 \mathrm{~s}$, and $95^{\circ} \mathrm{C}$ for $15 \mathrm{~s}$. The standard curve method and the 7900 HT Sequence 
Detection Systems Software (version 2.4; Applied Biosystems) were used for data analysis. The internal control genes used were GADPH, UXT, and RPS9; the list of target genes is reported in Supplemental Table S1 (https://doi.org/10.3168/jds.2017-13351). Primer design and evaluation were performed following established protocols in our laboratory (Bionaz and Loor, 2011).

\section{Western Blot}

The protocol for Western blot analysis was as previously described with modifications (Hosseini et al., 2015). Briefly, proteins $(20 \mu \mathrm{g}$ of total protein) were diluted with $4 \times$ Laemmli sample buffer (no. 161-0747; Bio-Rad, Hercules, CA) to a ratio of 3:1 and boiled at $95^{\circ} \mathrm{C}$ for $10 \mathrm{~min}$. Samples were then subjected to $10 \%$ SDS/PAGE at $120 \mathrm{~V}$ for approximately $120 \mathrm{~min}$ and then electrotransferred onto a polyvinylidene fluoride (PVDF) membrane (no. 162-0261; Bio-Rad) via the trans-blot SD semi-dry electrophoretic transfer cell (no. 170-3940; Bio-Rad). The PVDF membranes were blocked with $5 \%$ skim milk for $1 \mathrm{~h}$ at room temperature and were then incubated with the primary antibodies [anti-Akt, anti-Akt (Ser473), anti-mTOR, anti-mTOR (Ser2448), anti-4EBP1, anti-4EBP1(Thr37/46), anti-S6K1, anti-S6K1 (Thr389), anti-rpS6, anti-rpS6 (Ser235/236), anti-eIF2 $\alpha$, anti-eIF2 $\alpha$ (Ser21), antieEF2, and anti-eEF2 (Thr56)] overnight at $4^{\circ} \mathrm{C}$, followed by six 5 -min washes using Tris-buffered saline-Tween buffer. Subsequently, goat polyclonal secondary antibody incubation was performed at room temperature for $1 \mathrm{~h}$, followed by the same wash step. The PVDF membranes were visualized with the Clarity Western ECL substrate (no. 170-5060; Bio-Rad) and scanned using the ChemiDoc MP system (Bio-Rad). Band intensities were quantified using Image Lab software (version 3.0, Bio-Rad, Hercules, CA), and phosphorylation state was calculated as the intensity ratio of phosphorylated protein to total protein (arbitrary units). Glyceraldehyde-3-phosphate dehydrogenase was used as the internal reference protein to normalize protein expression. More details about antibodies are reported in Supplemental Table S2 (https://doi.org/10.3168/jds .2017-13351).

\section{Data Analysis}

All the real-time PCR and Western blot data with non-normal distribution were $\log _{2}$ transformed before statistical analysis, which was performed using the MIXED procedure in SAS (version 9.3; SAS Institute Inc., Cary, NC), with ratios of Lys to Met as a fixed ef- fect and individual cell culture well as a random effect. Treatment means were generated using the LSMEANS option and separated when they were significant with the PDIFF option. Statistical significance was considered at $P \leq 0.05$. For metabolomics, the chemometric models including supervised partial least squares discriminant analysis (PLS-DA) and orthogonal PLS-DA were obtained with MetaboAnalyst 3.0 (Xia and Wishart, 2011) using log-transformed and autoscaled data. Metabolites for which 30\% or more had missing data were removed from analysis; the rest of the missing values for a particular metabolite were imputed with the observed minimum detection value, assuming their level was below the instrument detection limit. A probability level of $P<0.05$ was considered statistically significant. Statistical models were validated by 10 -fold cross-validation and response permutation with 500 random reclassifications. A regression coefficient plot with $95 \%$ jackknifed confidence interval was used to determine which metabolites drove an observed clustering pattern. Parameters $\mathrm{R}^{2} \mathrm{Y}$ and $\mathrm{Q}^{2}$ greater than 0.5 were regarded as indicators of a robust model with prominent predictive ability. Metabolites with variable importance for projection (VIP) values exceeding 1.5 were selected as being significantly different across treatments (Storey, 2002; Wiklund et al., 2008; Issaq and Veenstra, 2013).

\section{RESULTS}

\section{Metabolomics}

In total, 162 compounds were identified and quantified by GC-MS. The PLS-DA and orthogonal PLS-DA analysis revealed unique clusters between any 2 treatments (Figure 1 and 2). The parameters $\mathrm{R}^{2} \mathrm{Y}$ and $\mathrm{Q}^{2}$ are both used for evaluating the reliability of the model. The parameter $R^{2} Y$ was greater than 0.995 in all cases, suggesting reliability of the model used. Similarly, most $\mathrm{Q}^{2}$ values were greater than 0.57 , suggesting predictive ability of the model used in this study. The top 15 significantly different metabolites (VIP $>1.5, P<0.05$ ) between any 2 treatments are depicted in the VIP plots (Figure 3).

Compared with IPAA, most metabolites with the lowest concentrations were associated with LM2.5, including EAA (Phe, Leu, Ile, and Val), NEAA (Glu), and putrescine. Relative to IPAA, the highest Lys:Met ratio (LM2.0) resulted in greater concentrations of 11 metabolites, including Met, Pro, Glu, Gln, Asp, and Gly. Compared with LM2.5, the concentration of 15 metabolites was greater in LM2.0, including EAA (Met, Ile, and Leu) and NEAA (Pro, Glu, Gly, Ala, and Gln). 

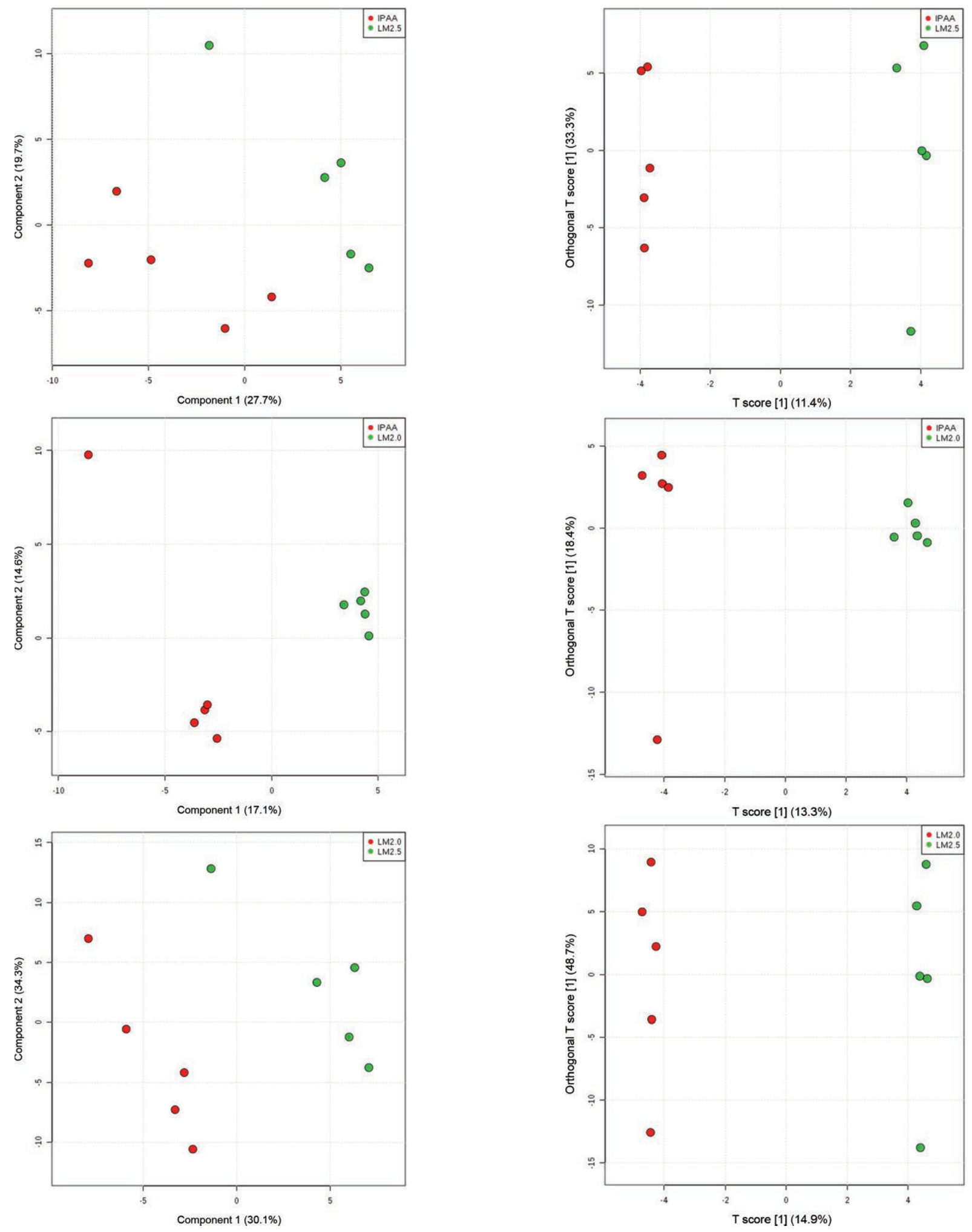

Figure 1. Partial least squares discriminant analysis of mammary cellular extracts after incubation with the ideal AA ratio (Lys:Met 2.9:1; IPAA) or treatments containing Lys:Met at 2.5:1 (LM2.5) and 2.0:1 (LM2.0). IPAA versus LM2.5 (top panel), IPAA versus LM2.0 (middle panel), and LM2.5 versus LM2.0 (bottom panel). Color version available online.

Figure 2. Orthogonal partial least squares discriminant analysis of mammary cellular extracts after incubation with the ideal AA ratio (Lys:Met 2.9:1; IPAA) or treatments containing Lys:Met at 2.5:1 (LM2.5) and 2.0:1 (LM2.0). IPAA versus LM2.5 (top panel), IPAA versus LM2.0 (middle panel), and LM2.5 versus LM2.0 (bottom panel). Color version available online. 


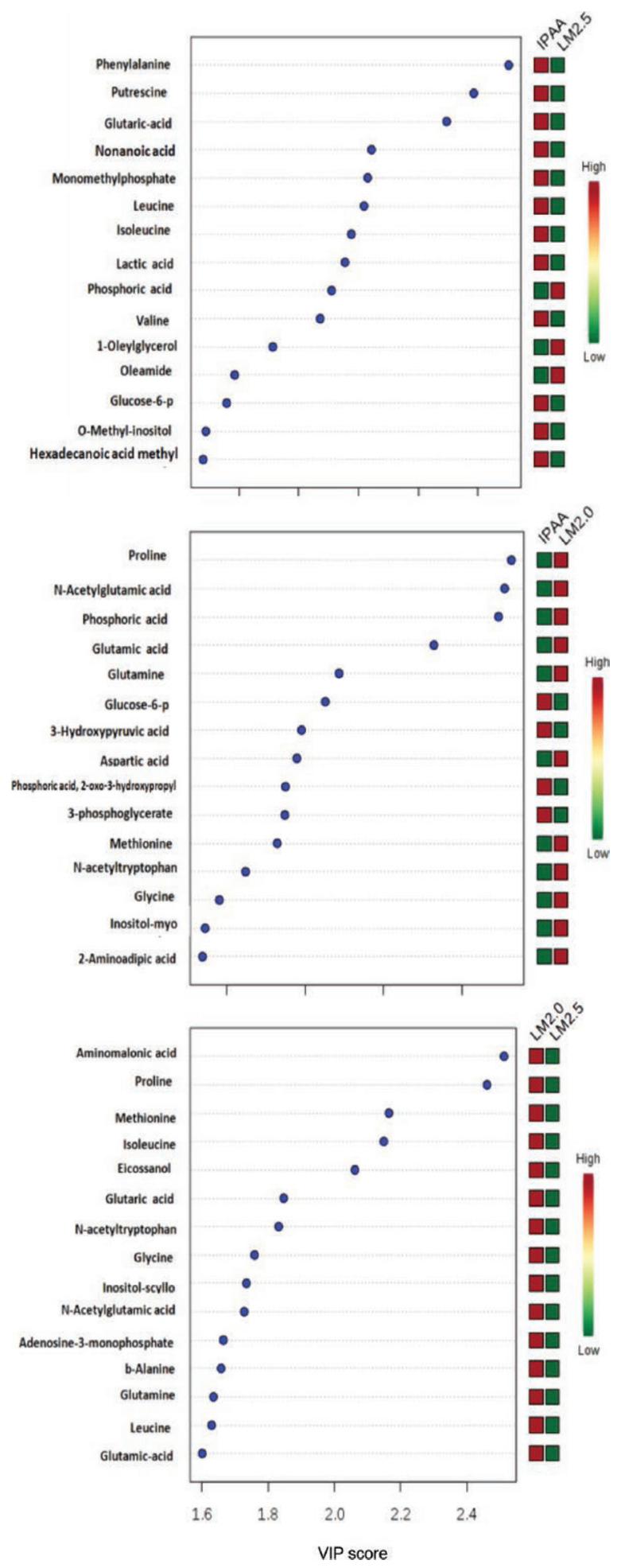

Figure 3. Ranking of metabolites in cellular extracts from mammary cells incubated with the ideal AA ratio (Lys:Met 2.9:1; IPAA) or treatments containing Lys:Met at 2.5:1 (LM2.5) and 2.0:1 (LM2.0). Metabolites are ranked by variable importance in projection analysis (VIP). The intensity of the red and green colors in the squares denotes the relative increase or decrease in concentration. IPAA versus LM2.5 (top panel), IPAA versus LM2.0 (middle panel), and LM2.5 versus LM2.0 (bottom panel). Color version available online.

\section{mRNA Expression}

The effects of Lys:Met ratio on mRNA expression of AA transporters and $\beta$-casein are reported in Table 2. Compared with IPAA, both LM2.5 and LM2.0 had greater $(P<0.01)$ mRNA expression of SLC3A2 (solute carrier family 3 member 2 ), a transporter of L-type AA. However, compared with IPAA, the decrease in Lys:Met ratio due to LM2.5 and LM2.0 led to lower expression $(P<0.05)$ of $S L C 7 A 5$ (solute carrier family 7 member 5 , an L-type AA transporter), SLC36A1 (solute carrier family 36 member 1 , a proton/AA transporter), SLC38A2 (solute carrier family 38 member 2 , an $\mathrm{Na}^{+}$-dependent/neutral AA transporter), SLC38A9 (solute carrier family 38 member 9 , an $\mathrm{Na}^{+}$-dependent/ neutral AA transporter), and SLC43A1 (solute carrier family 43 member 1 , an L-type AA transporter). Greater expression of SLC38A9 and SLC43A1 was also observed in response to the highest level of Met supplementation (LM2.0) compared with intermediate supplementation of Met (LM2.5).

Compared with IPAA, $\beta$-casein expression was lower $(P<0.05)$ in LM2.5. A tendency $(P=0.06)$ for lower $\beta$-casein expression also was observed in LM2.0 relative to IPAA, whereas no difference $(P>0.05)$ in $\beta$-casein expression was observed between LM2.5 and LM2.0.

\section{Protein Expression and Phosphorylation Status of the mTOR Pathway}

The effect of Lys:Met ratio on protein expression and phosphorylation status of proteins in the mTOR signaling pathway is reported in Table 3. Compared with IPAA, an increase in Met supplementation resulted in a greater $(P<0.05)$ total protein abundance of mTOR, but only LM2.0 led to greater $(P<0.05)$ total eIF $2 \alpha$ protein expression. The highest degree of phosphorylation of Akt, mTOR, and S6K1 also was observed in LM2.5 (intermediate increase in Met supplementation) compared with IPAA. A further increase in Met supplementation (LM2.0) led to a decrease $(P<0.01)$ in pS6K1 compared with IPAA and LM2.5. Compared with IPAA, an increase in Met supplementation (LM2.5 and LM2.0) resulted in a greater $(P<0.01)$ ratio of p-AKT: AKT but lower $(P<0.01)$ p-mTOR:mTOR. There was no change $(P>0.05)$ in p-4EBP1:4EBP1, pS6K1: S6K1, p-RPS6:RPS6, p-eIF2 $\alpha: e I F 2 \alpha$, and p-eEF2: eEF2 ratios.

\section{DISCUSSION}

\section{AA Metabolism}

BCAA Metabolism. Changes in branched-chain AA (BCAA) concentrations have been associated 
Table 2. Effects of incubating mammary cells with the ideal AA ratio (Lys:Met 2.9:1; IPAA) or treatments containing Lys:Met at 2.5:1 (LM2.5) and 2.0:1 (LM2.0) on mRNA expression (log-scale) of AA transporters and $\beta$-casein ${ }^{1}$

\begin{tabular}{|c|c|c|c|c|c|}
\hline \multirow[b]{2}{*}{ Gene } & \multicolumn{3}{|c|}{ Treatment } & \multirow[b]{2}{*}{ SEM } & \multirow[b]{2}{*}{$P$-value } \\
\hline & IPAA & LM2.5 & LM2.0 & & \\
\hline SLC3A2 & $0.33^{\mathrm{b}}$ & $0.60^{\mathrm{a}}$ & $0.72^{\mathrm{a}}$ & 0.14 & $<0.001$ \\
\hline$S L C 7 A 5$ & $1.14^{\mathrm{a}}$ & $0.81^{\mathrm{b}}$ & $0.81^{\mathrm{b}}$ & 0.03 & $<0.001$ \\
\hline SLC36A1 & $1.11^{\mathrm{a}}$ & $0.94^{\mathrm{b}}$ & $0.96^{\mathrm{b}}$ & 0.04 & 0.055 \\
\hline SLC $38 A 2$ & $1.26^{\mathrm{a}}$ & $0.85^{\mathrm{b}}$ & $0.95^{\mathrm{b}}$ & 0.05 & $<0.001$ \\
\hline SLC $38 A 9$ & $1.05^{\mathrm{a}}$ & $0.83^{\mathrm{b}}$ & $0.90^{\mathrm{b}}$ & 0.01 & $<0.001$ \\
\hline$S L C 43 A 1$ & $1.20^{\mathrm{a}}$ & $0.64^{\mathrm{b}}$ & $0.93^{\mathrm{b}}$ & 0.05 & $<0.001$ \\
\hline$C S N^{2}$ & $1.56^{\mathrm{a}}$ & $1.04^{\mathrm{b}}$ & $1.06^{\mathrm{b}}$ & 0.18 & 0.085 \\
\hline
\end{tabular}

${ }_{\mathrm{a}, \mathrm{b}}$ Means in a row with different superscripts differ $(P<0.05)$.

${ }^{1}$ Data are LSM and SEM $(\mathrm{n}=5$ replicates/treatment).

with alterations in mammary AA uptake or intracellular protein degradation (Mackle et al., 1999; Manjarin et al., 2014). The greater intracellular BCAA in MEC incubated with IPAA agrees with work demonstrating decreased plasma BCAA levels in dairy cows receiving rumen-protected Met supplementation (Berthiaume et al., 2006). However, it is noteworthy that Met supplementation actually increased posthepatic BCAA supply in dairy cows, suggesting enhanced rather than decreased BCAA utilization in response to Met supplementation (Berthiaume et al., 2006; Yang et al., 2010). Therefore, we speculate that the lack of change in concentration of downstream metabolites of BCAA degradation (Gln, Ala; Holeček, 2002) as a result of increasing Met supplementation in culture medium is suggestive of BCAA being utilized for protein synthesis in MEC.

Aromatic AA Metabolism. Phenylalanine has recently been recognized as a potentially limiting AA. In contrast to Val and Leu, whose uptake by the mammary gland exceeds their secretion in milk, the amount of Phe extracted was shown to be equal to its amount secreted in milk (Iroshan et al., 2013). The enzyme Phe hydroxylase can metabolize Phe to generate Tyr; how-

Table 3. Effects of incubating mammary cells with the ideal AA ratio (Lys:Met 2.9:1; IPAA) or treatments containing Lys:Met at 2.5:1 (LM2.5) and 2.0:1 (LM2.0) on protein expression and phosphorylation status of signaling proteins ${ }^{1}$

\begin{tabular}{lccccc}
\hline & \multicolumn{3}{c}{ Treatment } & & \\
\cline { 2 - 3 } Item & IPAA & LM2.5 & LM2.0 & SEM & $P$-value \\
\hline Total protein & & & & \\
Akt & 6.47 & 7.78 & 5.74 & 0.80 & 0.234 \\
mTOR & $0.15^{\mathrm{b}}$ & $0.50^{\mathrm{a}}$ & $0.44^{\mathrm{a}}$ & 0.07 & 0.027 \\
4EBP1 & 0.72 & 0.94 & 1.43 & 0.26 & 0.187 \\
S6K1 & 4.11 & 5.03 & 2.56 & 1.04 & 0.102 \\
RPS6 & 7.38 & 9.55 & 5.16 & 2.04 & 0.347 \\
EIF2 $\alpha$ & $1.40^{\mathrm{b}}$ & $3.20^{\mathrm{ab}}$ & $4.04^{\mathrm{a}}$ & 0.60 & 0.025 \\
EEF2 & 0.60 & 0.66 & 0.85 & 0.23 & 0.739 \\
Phosphorylated protein & & & & \\
p-Akt & $0.54^{\mathrm{b}}$ & $1.00^{\mathrm{a}}$ & $0.69^{\mathrm{b}}$ & 0.08 & 0.005 \\
p-mTOR & $1.05^{\mathrm{b}}$ & $1.84^{\mathrm{a}}$ & $1.30^{\mathrm{b}}$ & 0.11 & 0.005 \\
p-S6K1 & $0.24^{\mathrm{b}}$ & $0.39^{\mathrm{a}}$ & $0.12^{\mathrm{c}}$ & 0.05 & $<0.001$ \\
p-RPS6 & 1.82 & 2.29 & 1.69 & 0.36 & 0.481 \\
p-EIF2 $\alpha$ & 0.76 & 0.91 & 0.84 & 0.20 & 0.872 \\
p-EEF2 & 9.63 & 11.82 & 13.22 & 2.65 & 0.638 \\
Ratio & & & & & \\
p-Akt:Akt & $0.08^{\mathrm{b}}$ & $0.13^{\mathrm{a}}$ & $0.12^{\mathrm{a}}$ & 0.01 & 0.002 \\
p-mTOR:mTOR & $7.18^{\mathrm{a}}$ & $3.81^{\mathrm{b}}$ & $3.21^{\mathrm{b}}$ & 0.52 & 0.004 \\
p-4EBP1:4EBP1 & 2.11 & 1.32 & 1.54 & 0.27 & 0.151 \\
p-S6K1:S6K1 & 0.06 & 0.08 & 0.05 & 0.01 & 0.135 \\
p-RPS6:RPS6 & 0.25 & 0.29 & 0.37 & 0.04 & 0.234 \\
p-EIF2 $\alpha: E I F 2 \alpha$ & 0.61 & 0.57 & 0.27 & 0.19 & 0.429 \\
p-EEF2:EEF2 & 18.2 & 19.9 & 17.4 & 3.03 & 0.847 \\
\hline
\end{tabular}

${ }^{\mathrm{a}-\mathrm{c}}$ Means in a row with different superscripts differ $(P<0.05)$.

${ }^{1}$ Data are LSM and SEM $(\mathrm{n}=5$ replicates/treatment). 
ever, the fact that we did not detect a significant difference in Tyr concentration between LM2.5 and IPAA indicates that all Phe might have been used for protein synthesis. Furthermore, considering that the same level of Phe was supplemented in IPAA and LM2.5, it seems plausible that the uptake of Phe might have been inhibited. It has been demonstrated that SLC7A5 is a major AA transporter with high affinity for BCAA and aromatic AA (Kanai et al., 1998). In the present study, lower concentrations of both BCAA and Phe with LM2.5 could be taken as an indication of competitive inhibition of uptake via the activity of SLC7A5. The lower mRNA expression of SLC7A5 compared with IPAA supports this idea.

The compound $N$-acetyltryptophan is structurally similar to Trp and has high affinity for SLC7A5 (Wegmann et al., 1978); thus, its accumulation might affect Phe uptake. In addition to that indirect effect on AA uptake, $N$-acetyltryptophan is commonly used as a protein stabilizer, particularly for albumin, due to its capacity for scavenging reactive oxygen species (Kouno et al., 2014). Whether the elevated intracellular concentrations of $\mathrm{N}$-acetyltryptophan with LM2.0 and LM2.5 versus IPAA can be regarded as an indication of better oxidative stress status in MEC merits further study. However, considering that both glutathione and taurine ultimately acquire sulfur from Met and that intracellular Met concentrations were increased in both LM2.0 and LM2.5, it is reasonable to speculate that increasing Met supplementation led to a decrease in oxidative stress in MEC, hence "sparing" molecules with antioxidant properties such as $N$-acetyltryptophan.

\section{Arg-Ornithine-Putrescine-Pro Metabolism.}

Putrescine is derived from the Arg-ornithine-putrescine metabolism pathway (Manjarin et al., 2014), and addition of putrescine in vitro increased the activity of mTOR signaling in porcine trophectoderm cells, leading to overall greater protein synthesis (Kong et al., 2014). The lower concentration of putrescine with LM2.5 versus IPAA suggests that maintaining IPAA helps promote putrescine production and downstream mTOR signaling. The increase in Pro and Glu concentrations in the LM2.0 treatment relative to IPAA and LM2.5 is suggestive of increased activity of D-amino oxidases via $\Delta 1$-l-pyrroline-5-carboxylate (P5C) generated from ornithine aminotransferase (Manjarin et al., 2014). The fact that we did not detect greater concentrations of $\mathrm{P} 5 \mathrm{C}$ in response to increasing Met concentrations support this idea. The ideal AA profile in IPAA (including optimal Lys:Met ratio of 2.9:1) and the lower putrescine are suggestive of greater activity of ornithine decarboxylase.

In addition to putrescine (an intermediate metabolite of Arg metabolism), $\mathrm{N}$-acetylglutamate (NAG) and
Pro, both of which are products of Arg metabolism, were responsive to level of Met supplementation. The higher concentration of NAG and Pro in response to the highest levels of Met (i.e., LM2.0) is suggestive of an induction in Arg catabolism. In nonruminant studies, it has been demonstrated that NAG activates carbamoylphosphate synthetase I, the first enzyme of Arg synthesis in the urea cycle (Caldovic et al., 2002). Proline is a downstream metabolite of Arg catabolism and is synthesized from P5C by P5C reductase (Manjarin et al., 2014). The biological reason for an increase in Arg metabolism with increased supplementation of Met is unclear. However, it would appear that maintaining a consistent supply of Met in the medium could lead to excess intracellular Met and induce a deficiency of Arg. This type of response underscores the importance of maintaining an appropriate balance of AA.

Met and Lys Metabolism. Although LM2.0 increased concentrations of various intracellular metabolites compared with IPAA (except for Met), few EAA increased in concentration (Ile, Leu). Furthermore, the fact that higher concentrations of Glu and Gln (both NEAA) were detected indicated that Met might have induced catabolism of other EAA at least in part to generate ATP (Bequette et al., 1998). We speculate that despite the increase in Met supply with LM2.0, EAA catabolism could potentially lead to lower availability of other EAA. Thus, based on our results, at the optimal Met concentration mammary cell utilization of AA for milk protein synthesis is greater, albeit with a lower efficiency of utilization of other EAA. Future studies could optimize other EAA ratios based on the ideal Met concentration to further enhance milk protein synthesis. Overall, the metabolomics analysis demonstrated that compared with LM2.5 and LM2.0, a positive response in milk protein synthesis with IPAA might in part be due to the availability of other EAA and NEAA.

The central role of Met and Lys as 2 of the mostlimiting AA for dairy cows is well established. However, less is known about the influence of intracellular Met concentration on the metabolism of Lys. In mammals, Lys is catabolized by condensing with 2-oxoglutarate to form saccharopine, which is then converted to $\alpha$-aminoadipic acid and Glu (Emery, 2013). The fact that both $\alpha$-aminoadipic acid and Glu were greater in LM2.0 compared with IPAA indicates that excess Met enhanced Lys catabolism. It is unclear whether this alteration was due to the higher intracellular Met inducing an imbalance in AA profiles. $\alpha$-Aminoadipic acid is ultimately converted to acetyl-CoA (Emery, 2013), and intracellular $\alpha$-aminoadipic acid was greater in LM2.0 but not LM2.5 compared with IPAA. Thus, it can be speculated that adjusting Lys:Met to 2.0:1 might have 
resulted in an imbalanced AA profile and consequently elevated degradation of Lys, which likely enhanced the Lys flux into the TCA cycle via acetyl-CoA.

\section{AA Transport}

Considering that the GC-MS analysis revealed that changes in intracellular AA concentrations and AA metabolism were likely induced by exogenous AA supplementation and that AA cannot diffuse across the cell membrane due to selective barrier function (Taylor, 2014), measuring changes in membrane-spanning AA transporters is helpful to understand mechanisms (Poncet and Taylor, 2013; Taylor, 2014). In the present work, the fact that LM2.5 and LM2.0 led to lower expression of various AA transporters (SLC7A5, SLC36A1, SLC38A2, SLC38A9, and SLC43A1) compared with IPAA suggested the existence of a mechanism whereby an increase in the supply of Met could elicit negative feedback on the uptake of AA when other EAA are balanced. The greater expression of SLC3A2 in response to increased Met supply agrees with previous data in human skeletal muscle in response to an increase in EAA supply (Drummond et al., 2010). The SLC3A2 gene encodes the $4 \mathrm{~F} 2$ cell-surface antigen heavy chain, which forms heteromeric AA transporters with different SLC7 proteins and is responsible for the transport of several AA (Palacín and Kanai, 2004; Fotiadis et al., 2013). Therefore, it seems plausible that greater Met supply exerts some direct or indirect control over the transcription of this transporter. Furthermore, because SLC7A5, SLC38A2, SLC36A1, and SLC38A9 are stimulated via mTOR activity when exogenous AA supplementation increases (Zheng et al., 2016), it seems plausible that the Met availability in MEC affects mRNA expression of AA transporters via mTOR. Overall, Met supply to MAC-T cells could potentially elicit indirect control on milk protein synthesis by regulating AA transport through its effect on transcription of those genes.

\section{mTOR Signaling Pathway Regulation}

The mTOR pathway is a key nutrient-sensing pathway that has been well studied in nonruminant models (Tokunaga et al., 2004); mTOR is a protein kinase and serves as the central regulator responsible for integrating various cellular signaling cascades, especially from AA (Zheng et al., 2016). In the present study, the fact that IPAA resulted in the highest p-mTOR:mTOR suggested that increasing the Met supply from a Lys: Met ratio of 2.9:1 would not promote milk protein synthesis through this signaling pathway. This response is consistent with data from studies using primary bovine mammary cells (Nan et al., 2014). In addition, the lack of significant difference in p-mTOR:mTOR as the Met supply increased also agrees with a study using mammary tissue slices from lactating cows (Arriola Apelo et al., 2014). Although not measured directly in the present study, together with previous results, the Met profile and that of other EAA in the IPAA treatment appear to be ideal for activating mTOR signaling.

Akt is a key upstream regulator of the mTOR pathway; hence, it also participates in the regulation of protein synthesis (Hemmings and Restuccia, 2012). Once phosphorylated, Akt could activate mTOR by phosphorylating the TSC2 or directly phosphorylating PRAS40, which is a subunit of the mTOR complex (Lien et al., 2016). In general, the phosphorylation status of Akt and mTOR should be consistent in response to alterations in intracellular EAA concentration. Hence, the opposite trend between those proteins in the present study was unexpected. It has been demonstrated that mTORC1 inhibition via rapamycin could induce feedback activation of Akt, suggesting that lower mTOR phosphorylation may lead to an increase in Akt phosphorylation status (Mi et al., 2015). Thus, it is plausible that increasing the Met supply in LM2.5 and LM2.0 inhibited mTOR phosphorylation, which triggered an increase in phosphorylation of Akt.

Several studies have shown that Akt activation is mainly dependent on stimulation of the PI3K-Akt pathway by insulin (Schwertfeger et al., 2001; Xie and Proud, 2014). Whether alterations in insulin signaling had a role in the response is not known, but it is well established that conditions that alter insulin sensitivity also alter the degree of protein phosphorylation (Giorgino et al., 1992). Because all treatments were incubated with the same dose of insulin but no significant difference in metabolite concentrations was observed related to insulin stimulation, we speculate that (among the EAA) Met could elicit a unique effect on the activation of Akt. That idea is consistent with previous data from primary bovine mammary cells (Burgos et al., 2010). The mechanism whereby the Akt senses the change in the supply of Met merits further study.

The lack of effect on 4EBP1, S6K1, rpS6, eEF2, and eIF $2 \alpha$ led us to examine the mRNA expression of $\beta$-casein (Kung et al., 2015), particularly because the MAC-T cell line does not secrete milk components and because mRNA expression of $\beta$-casein is positively correlated with milk yield (Tsiplakou et al., 2016). Thus, casein expression could serve as a proxy for the potential effects of Met supply on casein synthesis. A positive effect of EAA availability on mRNA expression of $\beta$-casein has been observed in primary bovine mammary cells (Chen et al., 2013). The fact that increasing the Met supply decreased CSN2 expression agrees with the downregulation of AA transporters, further sug- 
gesting that the intracellular supply of Met could trigger a mechanism to control AA availability for casein synthesis when the optimal ratios of EAA are achieved.

\section{CONCLUSIONS}

Our research provided more systematic evidence that supplementation of Met to reach a 2.9:1 Lys:Met ratio while maintaining optimal ratios of Phe, Thr, His, and Val relative to Lys could increase the concentration and utilization of intracellular EAA, in particular BCAA, potentially through improving the activity of AA transporters. Some of these transporters are partly controlled by mTOR signaling. Increasing Met to achieve Lys:Met ratios of less than 2.9 did not further optimize the utilization of intracellular EAA. Considering that EAA likely are metabolized by other tissues upon absorption, future in vivo studies could focus on whether formulating diets for optimal ratios of EAA in the MP is sufficient to provide the desired levels of these AA to the mammary cells.

\section{ACKNOWLEDGMENTS}

Xianwen Dong is a recipient of a doctoral scholarship from China Scholarship Council (Beijing).

\section{REFERENCES}

Ametaj, B. N., Q. Zebeli, F. Saleem, N. Psychogios, M. J. Lewis, S. M. Dunn, J. Xia, and D. S. Wishart. 2010. Metabolomics reveals unhealthy alterations in rumen metabolism with increased proportion of cereal grain in the diet of dairy cows. Metabolomics 6:583-594.

Appuhamy, J. A., A. L. Bell, W. A. Nayananjalie, J. Escobar, and M. D. Hanigan. 2011. Essential amino acids regulate both initiation and elongation of mRNA translation independent of insulin in MAC-T cells and bovine mammary tissue slices. J. Nutr. 141:1209-1215.

Armentano, L. E., S. Bertics, and G. Ducharme. 1997. Response of lactating cows to methionine or methionine plus lysine added to high protein diets based on alfalfa and heated soybeans. J. Dairy Sci. 80:1194-1199.

Arriola Apelo, S. I., L. M. Singer, X. Y. Lin, M. L. McGilliard, N. R. St-Pierre, and M. D. Hanigan. 2014. Isoleucine, leucine, methionine, and threonine effects on mammalian target of rapamycin signaling in mammary tissue. J. Dairy Sci. 97:1047-1056.

Bequette, B. J., F. Backwell, and L. Crompton. 1998. Current concepts of amino acid and protein metabolism in the mammary gland of the lactating ruminant. J. Dairy Sci. 81:2540-2559.

Berthiaume, R., M. Thivierge, R. Patton, P. Dubreuil, M. Stevenson, B. McBride, and H. Lapierre. 2006. Effect of ruminally protected methionine on splanchnic metabolism of amino acids in lactating dairy cows. J. Dairy Sci. 89:1621-1634.

Bertram, H. C., N. B. Kristensen, M. Vestergaard, S. K. Jensen, J. Sehested, N. C. Nielsen, and A. Malmendal. 2009. Metabolic characterization of rumen epithelial tissue from dairy calves fed different starter diets using $1 \mathrm{H}$ NMR spectroscopy. Livest. Sci. 120:127-134.

Bionaz, M., and J. J. Loor. 2011. Gene networks driving bovine mammary protein synthesis during the lactation cycle. Bioinform. Biol. Insights 5:83-98.
Burgos, S. A., M. Dai, and J. P. Cant. 2010. Nutrient availability and lactogenic hormones regulate mammary protein synthesis through the mammalian target of rapamycin signaling pathway. J. Dairy Sci. 93:153-161.

Caldovic, L., H. Morizono, Y. Xiaolin, M. Thompson, S. Dashuang, R. Gallegos, N. M. Allewell, M. H. Malamy, and M. Tuchman. 2002. Identification, cloning and expression of the mouse N-acetylglutamate synthase gene. Biochem. J. 364:825-831.

Chen, L., Z. Li, M. Wang, and H. Wang. 2013. Preliminary report of arginine on synthesis and gene expression of casein in bovine mammary epithelial cell. Int. Res. J. 3:17-23.

Donkin, S. S., G. Varga, T. Sweeney, and L. Muller. 1989. Rumenprotected methionine and lysine: Effects on animal performance, milk protein yield, and physiological measures. J. Dairy Sci. 72:1484-1491.

Drummond, M. J., E. L. Glynn, C. S. Fry, K. L. Timmerman, E. Volpi, and B. B. Rasmussen. 2010. An increase in essential amino acid availability upregulates amino acid transporter expression in human skeletal muscle. Am. J. Physiol. Endocrinol. Metab. 298:E1011-E1018.

Dumas, M. E., R. H. Barton, A. Toye, O. Cloarec, C. Blancher, A. Rothwell, J. Fearnside, R. Tatoud, V. Blanc, J. C. Lindon, S. C. Mitchell, E. Holmes, M. I. McCarthy, J. Scott, D. Gauguier, and J. K. Nicholson. 2006. Metabolic profiling reveals a contribution of gut microbiota to fatty liver phenotype in insulin-resistant mice. Proc. Natl. Acad. Sci. USA 103:12511-12516.

Emery, P. W. 2013. Amino acids: Metabolism A2. Pages $72-78$ in Encyclopedia of Human Nutrition (3rd ed.). B. Caballero, ed. Academic Press, Waltham, MA.

Fotiadis, D., Y. Kanai, and M. Palacin. 2013. The SLC3 and SLC7 families of amino acid transporters. Mol. Aspects Med. 34:139-158.

Giorgino, F., J.-H. Chen, and R. J. Smith. 1992. Changes in tyrosine phosphorylation of insulin receptors and a 170,000 molecular weight nonreceptor protein in vivo in skeletal muscle of streptozotocin-induced diabetic rats: Effects of insulin and glucose. Endocrinology 130:1433-1444.

Haque, M. N., H. Rulquin, A. Andrade, P. Faverdin, J. L. Peyraud, and S. Lemosquet. 2012. Milk protein synthesis in response to the provision of an "ideal" amino acid profile at 2 levels of metabolizable protein supply in dairy cows. J. Dairy Sci. 95:5876-5887.

Haque, M. N., H. Rulquin, and S. Lemosquet. 2013. Milk protein responses in dairy cows to changes in postruminal supplies of arginine, isoleucine, and valine. J. Dairy Sci. 96:420-430.

Hemmings, B. A., and D. F. Restuccia. 2012. PI3K-PKB/Akt pathway. Cold Spring Harb. Perspect. Biol. 4:a011189.

Holeček, M. 2002. Relation between glutamine, branched-chain amino acids, and protein metabolism. Nutrition 18:130-133.

Hosseini, A., M. R. Tariq, F. Trindade da Rosa, J. Kesser, Z. Iqbal, O. Mora, H. Sauerwein, J. K. Drackley, E. Trevisi, and J. J. Loor. 2015. Insulin sensitivity in adipose and skeletal muscle tissue of dairy cows in response to dietary energy level and 2,4-thiazolidinedione (TZD). PLoS One 10:e0142633.

Iroshan, I. H., H. Lapierre, and L. Doepel. 2013. The effect of a limited supply of phenylalanine, threonine, and tryptophan on milk yield and composition. Pages 115-116 in Energy and Protein Metabolism and Nutrition in Sustainable Animal Production. Springer.

Issaq, H. J., and T. D. Veenstra. 2013. Proteomic and Metabolomic Approaches to Biomarker Discovery. Academic Press, Waltham, MA.

Kadegowda, A. K., M. Bionaz, L. Piperova, R. Erdman, and J. Loor. 2009. Peroxisome proliferator-activated receptor- $\gamma$ activation and long-chain fatty acids alter lipogenic gene networks in bovine mammary epithelial cells to various extents. J. Dairy Sci. 92:4276-4289.

Kanai, Y., H. Segawa, K.-I. Miyamoto, H. Uchino, E. Takeda, and H. Endou. 1998. Expression cloning and characterization of a transporter for large neutral amino acids activated by the heavy chain of 4F2 antigen (CD98). J. Biol. Chem. 273:23629-23632.

Kong, X., X. Wang, Y. Yin, X. Li, H. Gao, F. W. Bazer, and G. Wu. 2014. Putrescine stimulates the mTOR signaling pathway and protein synthesis in porcine trophectoderm cells. Biol. Reprod. 91:106. 
Kouno, Y., M. Anraku, K. Yamasaki, Y. Okayama, D. Iohara, Y. Ishima, T. Maruyama, U. Kragh-Hansen, F. Hirayama, and M. Otagiri. 2014. $N$-acetyl-L-methionine is a superior protectant of human serum albumin against photo-oxidation and reactive oxygen species compared to $N$-acetyl-L-tryptophan. Biochim. Biophys. Acta 1840:2806-2812.

Kung, M. H., Y. J. Lee, J. T. Hsu, M. C. Huang, and Y. T. Ju. 2015. A functional study of proximal goat beta-casein promoter and intron 1 in immortalized goat mammary epithelial cells. J. Dairy Sci. 98:3859-3875.

Lien, E. C., C. A. Lyssiotis, and L. C. Cantley. 2016. Metabolic reprogramming by the PI3K-Akt-mTOR pathway in cancer. Recent Results Cancer Res. 207:39-72.

Mackle, T. R., D. Dwyer, and D. Bauman. 1999. Effects of branchedchain amino acids and sodium caseinate on milk protein concentration and yield from dairy cows. J. Dairy Sci. 82:161-171.

Manjarin, R., B. J. Bequette, G. Wu, and N. L. Trottier. 2014. Linking our understanding of mammary gland metabolism to amino acid nutrition. Amino Acids 46:2447-2462.

Mi, W., Q. Ye, S. Liu, and Q.-B. She. 2015. AKT inhibition overcomes rapamycin resistance by enhancing the repressive function of PRAS40 on mTORC1/4E-BP1 axis. Oncotarget 6:13962-16977.

Nan, X., D. Bu, X. Li, J. Wang, H. Wei, H. Hu, L. Zhou, and J. J. Loor. 2014. Ratio of lysine to methionine alters expression of genes involved in milk protein transcription and translation and mTOR phosphorylation in bovine mammary cells. Physiol. Genomics 46:268-275.

NRC. 2001. Nutrient Requirements of Dairy Cattle. 7th rev. ed. Natl. Acad. Press, Washington, DC.

Osorio, J. S., P. Ji, J. K. Drackley, D. Luchini, and J. J. Loor. 2013. Supplemental Smartamine M or MetaSmart during the transition period benefits postpartal cow performance and blood neutrophil function. J. Dairy Sci. 96:6248-6263.

Palacín, M., and Y. Kanai. 2004. The ancillary proteins of HATs: SLC3 family of amino acid transporters. Pflugers Arch. 447:490-494.

Poncet, N., and P. M. Taylor. 2013. The role of amino acid transporters in nutrition. Curr. Opin. Clin. Nutr. Metab. Care 16:57-65.

Reddi, S., N. Kumar, R. Vij, S. B. Mada, S. Kapila, and R. Kapila. 2016. Akt drives buffalo casein-derived novel peptide-mediated osteoblast differentiation. J. Nutr. Biochem. 38:134-144.

Rulquin, H., B. Graulet, L. Delaby, and J. Robert. 2006. Effect of different forms of methionine on lactational performance of dairy cows. J. Dairy Sci. 89:4387-4394.

Schwertfeger, K. L., M. M. Richert, and S. M. Anderson. 2001. Mammary gland involution is delayed by activated Akt in transgenic mice. Mol. Endocrinol. 15:867-881.
Storey, J. D. 2002. A direct approach to false discovery rates. J. R Stat. Soc. Series B Stat. Methodol. 64:479-498.

Sun, H. Z., D. M. Wang, B. Wang, J. K. Wang, H. Y. Liu, L. Guan, and J. X. Liu. 2015. Metabolomics of four biofluids from dairy cows: Potential biomarkers for milk production and quality. J. Proteome Res. 14:1287-1298.

Taylor, P. M. 2014. Role of amino acid transporters in amino acid sensing. Am. J. Clin. Nutr. 99:223S-230S

Tokunaga, C., K.-I. Yoshino, and K. Yonezawa. 2004. mTOR integrates amino acid- and energy-sensing pathways. Biochem. Biophys. Res. Commun. 313:443-446.

Tsiplakou, E., E. Flemetakis, E. D. Kouri, G. Karalias, K. Sotirakoglou, and G. Zervas. 2016. The effect of long-term under-and overfeeding on the expression of six major milk proteins' genes in the mammary tissue of goats. J. Anim. Physiol. Anim. Nutr. (Berl.) 100:422-430.

Wang, C., H. Y. Liu, Y. M. Wang, Z. Q. Yang, J. X. Liu, Y. M. Wu, T. Yan, and H. W. Ye. 2010. Effects of dietary supplementation of methionine and lysine on milk production and nitrogen utilization in dairy cows. J. Dairy Sci. 93:3661-3670.

Wegmann, H., H.-C. Curtius, and U. Redweik. 1978. Selective ion monitoring of tryptophan, N-acetyltryptophan and kynurenine in human serum: Application to the in vivo measurement of tryptophan pyrrolase activity. J. Chromatogr. A 158:305-312.

Wiklund, S., E. Johansson, L. Sjoestroem, E. J. Mellerowicz, U. Edlund, J. P. Shockcor, J. Gottfries, T. Moritz, and J. Trygg. 2008 Visualization of GC/TOF-MS-based metabolomics data for identification of biochemically interesting compounds using OPLS class models. Anal. Chem. 80:115-122.

Xia, J., and D. S. Wishart. 2011. Web-based inference of biological patterns, functions and pathways from metabolomic data using MetaboAnalyst. Nat. Protoc. 6:743-760.

Xie, J., and C. G. Proud. 2014. Signaling crosstalk between the mTOR complexes. Translation 2: 28174

Yang, W., H. Sun, Q. Wang, F. Liu, and Z. Yang. 2010. Effects of rumen-protected methionine on dairy performance and amino acid metabolism in lactating cows. Am. J. Anim. Vet. Sci. 5:1-7.

Yang, Y., N. Zheng, X. Zhao, Y. Zhang, R. Han, J. Yang, S. Zhao, S. Li, T. Guo, C. Zang, and J. Wang. 2016. Metabolomic biomarkers identify differences in milk produced by Holstein cows and other minor dairy animals. J. Proteomics 136:174-182

Zheng, L., W. Zhang, Y. Zhou, F. Li, H. Wei, and J. Peng. 2016. Recent advances in understanding amino acid sensing mechanisms that regulate mTORC1. Int. J. Mol. Sci. 17:E1636. 